\title{
Correlation between Health and Nutritional Status in Geriatric Population
}

\author{
Dheeraj Kumar, Namrata Rastogi, Ravi Madan
}

\begin{abstract}
Introduction: Impaired oral health interferes with the masticatory ability of an individual causing dietary restrictions, resulting in decreased intake for key nutrients, i.e. iron, fiber, vitamin $C$, etc. Therefore, the main aim of this survey was to assess whether the oral condition of geriatric population is directly or indirectly related to the intake of selected nutrients.
\end{abstract}

Aim: It is presumed that the number of teeth affect the type of food consumed by an individual. This choice of food may compromise the nutritional value of the diet. The aim of this study is to find a correlation between the nutritional statuses of an individual to the number of teeth present.

Materials and methods: The subjects from the local population available were equally divided on the basis of number of posterior occluding pairs (POP) presentand the detailed information about the quantity and quality of food consumed was collected and then this available data was converted to nutritional intake value and then statistical analysis was undertaken.

Results: It is seen that body mass index (BMI) has no correlation with the dental status of an individual, but nutrient intake is directly related to the number of POPS of natural teeth.

Conclusion: In the present study, it was observed that edentulous participants consumed less dietary and crude fibers and consumed more saturated fat and cholesterol than participants with 21 or more teeth. Therefore, one must actively improve the oral care throughout his life to further increase the overall quality of life.

Keywords: Nutritional status, Geriatrics, E dentulous, Epidemiological survey.

How to cite this article: Kumar D, Rastogi N, Madan R. Correlation between Health and Nutritional Status in Geriatric Population. World J Dent 2012;3(4):297-302.

\section{Source of support: Nil}

Conflict of interest: None declared

\section{INTRODUCTION}

Nutrition and nourishment are the most basic requirements of an individual for the protection of health and promotion of well-being, thereby influencing the quality of life of an individual. ${ }^{1}$ The primary function of the teeth is mastication, hence, tooth loss is likely to reduce masticatory abilities leading to detrimental changes in the food choices, thereby increasing the risk of certain systemic diseases. ${ }^{2-4}$ Survey conducted in late 1980 s and early 1990 s shows that $40 \%$ of adults older than 65 who were living in senior citizen centers were completely edentulous.

One of the most likely mechanisms by which impaired oral health may affect diet is that difficulty in chewing or loss of teeth causes dietary restrictions. ${ }^{2}$ It has been found that edentulous health professionals consumed fewer vegetables, less dietary fibers and carotene than people with 25 or more teeth. ${ }^{5-13}$ Tooth loss was associated with a lower intake of foods which are hard to chew, such as apples and carrots. Studies which have analyzed the effects of dental status on consumption of nonstarch polysaccharides (dietary fibers) reported a reduced intake with tooth loss. ${ }^{13,14}$

A ccording to the literature, edentulous individuals prefer soft and processed diet avoiding any fruit, vegetables and meals that were considered as difficult to chew and present a lower intake of vitamin C, calcium, nonstarch polysaccharides and proteins. ${ }^{15,16,19} \mathrm{M}$ oreover, it has been found out that these changes in dietary pattern have lead to a higher consumption of calories from foods rich in fat. In a 1994 review article, Willet $^{18}$ reported several associations between diet and systemic diseases. Increase in cholesterol and saturated fat and decrease in fiber, carotene and antioxidants intake could heighten the risk of cardiovascular diseases. ${ }^{17,19}$ Decrease in consumption of fruits, vegetables and carotenoids and vitamin C could increase cancer risk. Decrease in vitamin $C$ has been universally associated with cataracts. Decrease in fiber consumption could lead to increased risk of colorectal adenomas. ${ }^{17}$

Older people can be vulnerable to dietary restrictions due to other reasons also like disability, medical or social conditions. The evidence generally available in the literature suggest that for elderly population tooth loss may alter food choice, resulting in lower intake for key nutrients, such as iron and fiber. ${ }^{8}$ Research also indicates that loss of natural teeth causes' reduced masticatory efficiency even after replacement with dentures. ${ }^{2,14}$ Elders who reported chewing problems had significantly fewer teeth than those who did not report chewing problems. ${ }^{19}$ Studies evaluating associations between tooth loss and diet are few and have several limitations.

Till date, very little work has been done in India about the effects of the dental status on diet and nutrition, and more precisely in North India and whether oral and dental condition of elderly people will somehow affect the health and general well being of these individuals.

Therefore, the main aim of this survey was to assess the nutritional status of people 65 years and older to find out whether the dental status is related to the intake of selected vital nutrients. 


\section{MATERIALS AND METHODS}

The oral health survey was done in the local population of Lucknow which reported to the dental institute as well as various private clinics of Lucknow. The main idea is to ensure that a variety of people with different caste, tribe, culture and religion will come under the survey and will comprise the population of North India. The participants were randomly selected under the guidance of $W$ orld $\mathrm{H}$ ealth Organization (WHO). ${ }^{20}$ The individuals who were unable to participate either due to physical or mental reasons were excluded. A II the subjects signed an informed consent for the interview as well as the written questionnaires, ${ }^{18,21}$ which were prepared as per standardized natural probing questions. Complete details of sampling and weighing procedures are considered. ${ }^{22}$ The subjects were further divided according to the teeth present in the oral cavity. They were divided into four groups as follows: ${ }^{23}$

1. Totally edentulous patients

2. 1 to 10 teeth present

3. 11 to 20 teeth present

4. 21 or more teeth present.

Then the nutritional status of the subject was determined using the body mass index (BMI; established by WHO), ${ }^{24}$ which is as follows (Table 1):

- Underweight (less than 18.5)

- Normal (18.5-24.99)

- Overweight (25-29.99)

- Obese (greater than or equal to 30 ).

Height was measured with a portable stadiometer with participants being barefoot and head in NHP.W eight was measured to the nearest $100 \mathrm{gm}$ using a digital scale.

Furthermore, dental examination recorded the distribution of natural teeth, number of naturally occluding pair of teeth, spaces and partial dentures with detailed information about the condition of teeth in accordance with $\mathrm{WHO}^{24}$ guidelines. The number of natural posterior functional teeth or posterior occluding pairs (POPS) was established, ${ }^{22}$ and the subjects were then allocated into groups as follows:

1. NoPOP

2. 1 to $4 P O P$

3. 5 to $8 \mathrm{POP}$

4. $\geq 8 \mathrm{POP}$

Equal number of each subgroup ( $n=75$ ) was taken to avoid the discrepancy caused due to different number of subjects having different POPs. D etailed information about the quantities of food and nutrients consumed was collected. Participants or their caretakers were asked to keep a '4-day' weighted record of all the food and drinks consumed. This was carried out on nonconsecutive days, in order to reduce the variations in usual intake not only between people but also from day-to-day for each person..$^{25,26}$ This is a reliable instrument for use in epidemiological studies because it is easy to use even by individuals with a low level of education and it is less expensive also, thus enabling it to be used in low income countries. The data from these records were converted into nutrition intake data ${ }^{27}$ and the nutritive value of each food intake was converted using HG-72 Nutritive V alue of food by the US Department of A griculture (National A griculture Library) ${ }^{28}$ available on the website (www.nal.usda.gov/fnic/foodcomp/data). The statistical analysis includes descriptive and inferential analysis using a $5 \%$ significant level. The term 'not statistically significant' indicates significance less than $5 \%$ level. Differences between means were evaluated using 'ANOVA', according to the normalcy of the data. A ssociations betw een categorical variables were done using 'Chi-square analysis' and 't-test'.

\section{RESULTS}

The working sample for the oral health survey, drawn from those who completed the food diary, represented $59 \%$ of the issued sample. of the individuals who participated in the dietary assessment oral examination a high DM FT index (mean, 27.81) was observed. M issing components showed a high preval ence (mean, 24.70; median, 28; SD, 8.82) and accounted for $88.8 \%$ of the index. M ost of the subjects were in the edentulous group (44.5\%). Only $12.4 \%$ had 21 or more teeth, $25.8 \%$ had one to 10 teeth and $17.3 \%$ were found to have 11 to 20 teeth and only $12.4 \%$ were found to have $\geq 21$ teeth (Table 1 ).

A fter collection and subsampling of the different variety of edentate groups, equal number of sample was divided into each group, i.e.

- Edentate group (no POP)- 75 sample size

- 1-10 teeth (1-4 POP) - 75

- 11-20 teeth (5-8 POP) - 75

- $M$ ore than 20 teeth ( $\geq 8$ POP) -75

Therefore, the final sample comprised of 300 elderly, of whom $67.3 \%$ were females with age ranging from 65 to 85 years (mean, 68.2 years) with $43 \%$ of participants in the 65 to 72 years old group. M ost of the participants had a minimum education of high school and a minimum earning of ₹ $10,000 /$ - per month. A ccording to these results, both the number of teeth and POPs of natural teeth were associated with age, educational level and income ( $p \leq$ 0.001 ). The gender was also associated with the number of teeth and POPs ( $\leq \leq 0.001$ and $p=0.028$ respectively).

The mean w eight was $65.26 \mathrm{~kg}(\mathrm{SD}, 13.64)$ and the mean height was $1.56 \mathrm{~m}$ (SD, 0.09). Nutritional assessment was 
Correlation between Health and Nutritional Status in Geriatric Population

Table 1: Distribution of $\mathrm{BMI}$ according to the number of teeth

\begin{tabular}{|c|c|c|c|c|c|c|c|c|c|c|}
\hline \multirow[t]{2}{*}{ BMI } & \multicolumn{2}{|c|}{ Edentate } & \multicolumn{2}{|c|}{$\begin{array}{l}1-10 \\
\text { teeth }\end{array}$} & \multicolumn{2}{|c|}{$\begin{array}{l}11-20 \\
\text { teeth }\end{array}$} & \multicolumn{2}{|c|}{$\begin{array}{l}21 \text { or more } \\
\text { teeth }\end{array}$} & \multicolumn{2}{|c|}{ Total } \\
\hline & $\bar{n}$ & $\%$ & $n$ & $\%$ & $\mathrm{n}$ & $\%$ & $\mathrm{n}$ & $\%$ & $\mathrm{n}$ & $\%$ \\
\hline Underweight & 8 & 1 & 6 & 0.7 & 0 & 0 & 3 & 0.4 & 17 & 2.1 \\
\hline Normal range & 125 & 15.5 & 58 & 7.2 & 46 & ‘5.7 & 34 & 4.2 & 263 & 32.5 \\
\hline Overweight & 135 & 16.7 & 91 & 11.2 & 69 & 8.5 & 45 & 5.6 & 340 & 42.0 \\
\hline Obese & 92 & 11.4 & 54 & 6.7 & 25 & 3.1 & 18 & 2.2 & 189 & 23.4 \\
\hline Total & 360 & 44.5 & 209 & 140 & 140 & 17.3 & 100 & 12.4 & 809 & 100 \\
\hline
\end{tabular}

$\chi^{2}=14.2(d f=9) ; p=0.116$; No significant difference-groups were matched for number of teeth

carried out among various groups and it was found that dentate participants had higher intakes than the edentulous. From Table 1, it is evident that there was no statistically significant difference between basal metabolic rate and dental status.

Table 2 shows the result of descriptive analysis and analysis of variance (A NOV A) for the variables related to nutrient intake in relation to the number of POPs of natural teeth. Table 3 shows the result of multiple comparison analysis between the two variants.

\section{DISCUSSION}

From previous studies, it is evident that chewing and masticatory efficiency are affected by oral health and specifically by the number and distribution of natural teeth ${ }^{9}$ present. $M$ arcenes et al ${ }^{15}$ reported that the number of teeth
Table 3: Multiple comparison between the number of POP and mean nutrient intake (independent samples t-test)

\begin{tabular}{llcl}
\hline Nutrients & & POP (pairs) & p-value \\
\hline Protein & 0 pair & $1-4$ & 0.030 \\
& & $5-8$ & 0.025 \\
& $1-4$ pair & $5-8$ & 0.973 \\
\hline
\end{tabular}

All the calculations have been done using the following three tests:

- Chi-square: http://www.physics.csbsju.edu/stats/contingency_ NROW NCOLUMN form.html

- ANOVÄ: http://www.danielsoper.com/statcalc/calc43.aspx

- T-test: www.graphpad.com: http://www.graphpad.com/quickcalcs/ ttestl.cfm

may not be the most suitable measurement of masticatory function. Having posterior teeth which occlude may be more significant than having a poorly distributed teeth. Hildebrant et $\mathrm{al}^{29}$ found that elderly people with a reduced number of

Table 2: Descriptive analysis and ANOVA for the number of POPs and the mean intake of nutrients ( $n=50$ for each POP)

\begin{tabular}{|c|c|c|c|c|c|}
\hline Nutrient & $\begin{array}{l}\text { Posterior } \\
\text { occluding pairs }\end{array}$ & Mean & $\begin{array}{l}\text { Standard } \\
\text { deviation }\end{array}$ & ANOVA-test & p-value \\
\hline \multirow{3}{*}{ Vitamin C } & 0 pair & 95.1 & 220.2 & 0.634 & 0.065 \\
\hline & 1-4 pairs & 127.4 & 244.2 & & \\
\hline & $\geq 8$ pairs & 153.6 & 271.9 & & \\
\hline \multirow[t]{3}{*}{ Calcium } & $\overline{0}$ pair & 378.9 & 211.7 & 2.809 & 0.013 \\
\hline & 1-4 pairs & 477.7 & 243.8 & & \\
\hline & $\geq 8$ pairs & 508.2 & 365.0 & & \\
\hline \multirow[t]{3}{*}{ Calories } & $\overline{0}$ pair & 1285.4 & 577.1 & 3.006 & 0.009 \\
\hline & 1-4 pairs & 1523.4 & 571.4 & & \\
\hline & $\geq 8$ pairs & 1301.4 & 534.1 & & \\
\hline \multirow[t]{3}{*}{ Carbohydrate } & 0 pair & 169.8 & 68.8 & 2.237 & 0.027 \\
\hline & 1-4 pairs & 197.5 & 79.3 & & \\
\hline & $\geq 8$ pairs & 195.1 & 74.0 & & \\
\hline \multirow[t]{3}{*}{ Iron } & $\overline{0}$ pair & 9.1 & 4.6 & 2.605 & 0.019 \\
\hline & 1-4 pairs & 11.0 & 5.2 & & \\
\hline & $\geq 8$ pairs & 11.3 & 5.4 & & \\
\hline \multirow[t]{3}{*}{ Dietary fiber } & $\overline{0}$ pair & 8.7 & 6.8 & 0.831 & 0.049 \\
\hline & 1-4 pairs & 10.4 & 7.3 & & \\
\hline & $\geq 8$ pairs & 10.7 & 7.0 & & \\
\hline \multirow[t]{3}{*}{ Phosphorus } & $\overline{0}$ pair & 292.3 & 180.7 & 2.583 & 0.002 \\
\hline & 1-4 pairs & 367.2 & 203.6 & & \\
\hline & $\geq 8$ pairs & 379.6 & 230.1 & & \\
\hline \multirow[t]{3}{*}{ Protein } & $\overline{0}$ pair & 56.1 & 24.9 & 3.177 & 0.005 \\
\hline & 1-4 pairs & 68.2 & 29.7 & & \\
\hline & $\geq 8$ pairs & 69.3 & 29.0 & & \\
\hline
\end{tabular}

For all the nutrients, the minimum intake was for 0 pair $P O P$, for vitamin $C$, calcium, phosphorus and protein the intake was maximum for 5 to 8 pair POP consumed, whereas the intake for carbohydrate, iron and dietary fiber was maximum for 1 to 4 pair POP. However, ANOVA revealed significant intergroup difference for protein only. As ANOVA revealed significant difference for protein only, hence, multiple comparisons were made only for protein intake 
natural maxillary teeth occluding with natural mandibular teeth avoided stringy foods (including meat), crunchy foods (including vegetables and fibers) and dry solid foods. B ut from the available review of literature, ${ }^{30}$ it can be clearly seen that there is still very little information available about the food intake and the nutritional status of the elderly among the local population of L ucknow. Therefore, the main aim of the study is to find the nutritional status of the local population with different number of teeth present.

A s evident from Table 1, no significant association was found between the number of teeth present and B M I, which is in agreement with the findings of $\mathrm{M}$ ojon et $\mathrm{al}^{16}$ and $\mathrm{L}$ ee et al. ${ }^{31} \mathrm{~B}$ ut in contrast Shayoun et a ${ }^{32}$ observed a significant relation between these two variables.

$M$ arcenes et $\mathrm{al}^{15}$ (also Lee et al) ${ }^{31}$ in support of our findings state that the frequency of the distribution of the B M I was similar in dentate and edentulous individuals. $\mathrm{He}$ also observed that those having less than 21 natural teeth $(\geq 5-8$ POP) had a greater chance $(p=0.036)$ of being obese than with having more number of teeth.

However, the relationship between nutrient intake and the number and distribution was more difficult to establish, perhaps because it was less pronounced and also because of the smaller number of subjects involved and the heterogeneity of the dentate group. Nevertheless, people with 21 or more natural teeth consumed more of the majority of nutrients than those with fewer. This is in line with the findings from the survey regarding eating ability ${ }^{12}$ (Sheiham et al 1999) and provides further evidence that having 21 or more natural teeth is consistent with a good dietary capability and optimal nutritional intake. On the other hand, our findings are different from the ones who, i.e. Osterberg et al, ${ }^{7}$ observed that no significant relation existed between dental state and dietary intake when single nutrients were considered. Shinkai et al ${ }^{33}$ found that occlusal impairment is related to a reduced oral function and not with the quality of diet which varied as a function of sex, ethnicity and age. $G$ reska et al ${ }^{34}$ concluded that tooth loss and denture wearing is associated with a decrease in adequacy of the diet, but not with a change in diet pattern. These authors highlighted the role of overall diet quality instead of diet and nutrition in terms of its isolated components.

A nother important finding is that intake of dietary fiber and vitamin C (Table 2) was much higher in people with more teeth and significantly associated with the number of teeth and occluding pairs of posterior teeth but no high statistically significance is established. These dietary fibers derived from food, such as fresh fruits and its derivatives were similarly associated. According to the literature, ${ }^{10,13}$ the lower intake of vitamin $C$ is related to a lower consumption of key foods that are considered as hard to chew by majority of individuals with a highly impaired dentition. Shayoun et al ${ }^{32}$ al so found that fiber intake among people with five or more pairs of posterior teeth was higher than in those with no pairs, further confirming the report by Sheiham et $\mathrm{al}^{35}$ that dental status is related to the intake of dietary fiber. Dietary fiber is an important component of diet, associated particularly with gastrointestinal health. ${ }^{36}$ This relationship emphasizes the role that maintenance of functional and natural dentition may have in improving the general health of the elderly.

In the present study (Table 2), the mean intake of all the nutrients is different within subgroups $(p<0.005)$ except for vitamin $C$ and dietary fiber. Comparison is done for most nutrients and it is found that the mean intake was significantly less in 'no posterior occluding teeth' (POP) as compared to 1 to 4 POP groups and 5 to 8 POP, suggesting a significantly lower average intake in those elderly with no POP of natural teeth. For all the nutrients, the minimum intake was in those individuals with no POP for vitamin C, iron, phosphorus and calcium and protein which increase as the number of POP increases with a maximum of $\geq 8$ POP.

How ever, highly significant intergroup difference is for proteins only ( $p \leq 0.005$; Table 3 ). A s far as carbohydrates and calories are concerned, intake for carbohydrates and calories was maximum for 1 to 4 POP which decreases in both 'no occluding pair of teeth' and more 'number of POP' of teeth. This relation was also noted by Lee et al, ${ }^{31}$ who found from multilevel analysis that edentulism increases the chance of $>5 \%$ weight increase in 1 year $(O R=1.73$; $\mathrm{Cl}=1.17-2.57 ; p=0.006$ ) whereas Raven et $\mathrm{al}^{37}$ found a statistically significant difference concluding that underweight being related to a highly impaired dentition and overweight to a less impaired dental condition.

It is suggested that subjects having 5 to 8 or more POP will be able to chew more of fibrous and crunchy diet reducing the carbohydrates and calorie content and increasing the fibrous and nutrient content of body whereas those subjects having no or 1 to 4 POPs will be on an easily chewable and soft diet causing an increase of carbohydrate and fat content, causing overweight and obesity (Table 2). A s evident from the Table 2, the differences in diet between different POPs are significant but small. However, these small detrimental effects of tooth loss on diet could lead to increased disease risk. Rimm et al in a study, evaluated the effects of fiber intake on myocardial infarction risk. ${ }^{38} \mathrm{~B}$ ased on their conclusions, we expect that $1 \mathrm{gm}$ difference in dietary fiber intake between dentate and edentulous could lead to approximately $2 \%$ increased risk of myocardial 
Correlation between Health and Nutritional Status in Geriatric Population

infarction. Considering the high prevalence of edentulousness, we would suggest that a fair number of individuals may be at increased risk for diseases, such as heart disease and cancer.

Despite the lack of association between the number of teeth and BMI, it is also important to mention that, in this study, subjects are heavily represented by the group with poor dentition, as compared to the small proportion of the subjects with POPs, which might mask some association with BMI.

It is worth while pointing out that this study was limited by its cross-sectional as well as limited number of subjects in the survey design and, therefore, lacks sufficient power to establish a cause effect relationship, thereby demonstrating the need to carry out further Iongitudinal studies, especially in devel oping countries where both tooth loss and overweight still acts as a major public health problem and need to be tackled.

\section{CONCLUSION}

As we now know that BMI is not related to the number of teeth present but the reduced number of POPs of teeth may show a decreased intake of food and therefore the nutrients by the elder people, indicating that the dental health status may affect the nutritional health as defined by clinical measures.

Considering the high prevalence of edentulous individuals at this age especially in developing countries like India, these results in broader sense highlight the importance of ensuring appropriate dental care for the whole population and not only in old age. Improved oral care throughout life will increase the overall quality of life in future generations of this fast growing segment, emphasizing the need for the integration of dietician and dental professional in the promotion of oral and consequently overall health of individuals.

\section{REFERENCES}

1. N'gom PI, Woda A. Influence of impaired mastication on nutrition. J Prosthet Dent 2002;87:667-73.

2. Carlos JP, W olfe M D. M ethodological and nutritional issues in assessing oral health of aged subjects. A m J Clin Nutr 1989;50:1210-18.

3. Posner BM, Jette A, Smigelski C, Miller D, M itchell P. Nutritional risk in New England Elders. J Gerontol 1994;49:M 123-32.

4. M ojon P, Rentsch A, Budtz-J orgensen E. Relationship between prosthodontic status, caries and periodontal disease in a geriatric population. Int J Prosthodont 1995;8:564-71.

5. Y urkstas AR, Emerson WH. Dietary selection of persons with natural and artificial teeth. J Prosthet Dent 1964;14:695-97.
6. Heath M R . D ietary selection by elderly persons related to dental state. Br Dent J 1972;132:145-48.

7. Osterberg $T$, Steen $B$. Relationship between dental state and dietary intake in 70-year-old males and females in Goteborg, Sweden: A population study. J Oral Rehabil 1982;9:509-21.

8. Chauncey $H H, M$ uench ME, K apur KK, W ayler $A H$. The effect of the loss of teeth on diet and nutrition. Int Dent J 1984;34: 98-104.

9. Geissler CA, B ates JF. The nutritional effects of tooth loss. A m J Clin Nutr 1984;39:478-89.

10. Papas A S, Palmer CA, R ounds M C, et al. The effects of denture status on nutrition. Spec Care Dent 1998;18:17-25.

11. Hollister MC, W eintraubs JA. The association of oral status with systemic health, quality of life, and economic productivity. J Dent Educ 1993;57:901-12.

12. Sheiham A, Steele J G, M arcenes W, et al. The impact of oral health on stated ability to eat certain foods: Findings from the National Diet and Nutrition Survey of older people in Great Britain. Gerodontology 1999;16:11-20.

13. Joshipura KJ, Willet WC, Douglass CW. The impact of edentulousness on food and nutrient intake. J A m Dent A ssoc 1996;127:459-67.

14. M oynihan PJ .The relationship betw een diet, nutrition and dental health: An overview and update for the $90 \mathrm{~s}$. Nutr Res Rev 1995;8:193-224.

15. M arcenes W, Steele J G, Sheiham A, W all AW G. The relationship betw een dental status, food selection, nutrient intake, nutritional status, and body mass index in older people. Cad Saude Publica 2003;19:809-16.

16. M ojon $P, B$ udtz-J orgensen $E$, Rapin C. The relationship between oral health and nutrition in very old people. Age Ageing 1999;28:463-68.

17. Ritchie CS, J oshipura K, H ung H, D ouglass CW. Nutrition as a mediator in the relation between oral and systemic disease: A ssociations between specific measures of adult oral heal th and nutrition outcomes. Crit Rev Oral Biol M ed 2002;13:291-300.

18. Willet WC. Diet and health: What should we eat? Science 1994;264:532-37.

19. K rall E, Hayes $C, G$ arcia R. How dentition status and masticatory function affect nutrient intake. J A m Dent A ssoc 1998;129: 1261-69.

20. WHO. Health of the elderly. World Health Organization technical report series 779. Geneva: WHO, 1989.

21. A dulyanon S, Sheiham AC. O ral impact on daily performances in measuring oral health and quality of life. In: Slade GD, (Ed). Dental ecology. Chapel Hill: University of North Carolina 1997; 151-60.

22. Finch SA, D oyle W, L owe C, et al. National Diet and N utrition Survey: People aged 65 and over, 1994-1995 [computer file], 2nd ed. Essex, UK : Colchester, 2001.

23. de A ndradeFB, deFranca Caldos A J r, K itoko PM . R elationship between oral health, nutrient intake and nutritional status in a sample of Brazilian elderly people. Gerodontology 2009 Mar;26(1):40-45.

24. WHO. Physical status: The use and interpretation of anthropometry. Report of a W HO expert committee. Technical report series number 854. Geneva: WHO, 1995.

25. Thompson FE, Byers T. Dietary assessment resource manual. J Nutr 1994;124:2245S-317S. 
26. Holmes B, Dick K, Nelson M. A comparison of four dietary assessment methods in materially deprived households in England. Public Health N utr 2008 M ay;11(5):444-56.

27. Gopalan C, Shastri BVR, B alsubramanian SC. Nutritive value of Indian foods. National Institute of Nutrition (NIN). Indian Council of M edical Research, Hyderabad, India 1985.

28. Nutritive value of foods. A vailable from: www.nal.usda.gov/ fnic/food com/data/table http://ndb.nal.usda.gov.

29. Hilderbrandt GH, Dominguez BL, Schork MA, Loesche WJ. Functional units, chewing, swallowing and food avoidance among elderly. J Prosthet Dent 1997;77:588-95.

30. WHO. K eep fit for life. M eeting the nutritional needs of older persons. Geneva: W HO, 2002.

31. Lee JS, W eyant RJ, Corby P, et al. Edentulism and nutritional status in a biracial sample of well-functioning, communitydwelling elderly: The health, aging and body composition study. A m J Clin Nutr 2004;79:295-302.

32. Shayoun NR, Lin C, K rall E. Nutritional status of the older adult is associated with dentition status. J A m Diet Assoc 2003;103:61-66.

33. Shinkai RSA, Hatch JP, Sakai S, et al. O ral function and diet quality in a community based sample. J Dent Res 2001;80: 1625-30.

34. Greska LP, Parraga JM, Clark CA. The dietary adequacy of edentul ous adults. J Prosthet D ent 1995;73:142-45.

35. Sheiham A, Steele JG, M arcenes W, et al. The relationship among dental status, nutrient intake and nutritional status in older people. J Dent Res 2001;80:408-13.
36. Brodeur J R, L aurin D, V allee M, Lachapelle D. N utrient intake and gastrointestinal disorders related to masticatory performance in the edentulous elderly. J Prosthet Dent 1993;70:468-73.

37. Rauen M S, M oreira EA, Calvo M C, et al. Oral condition and its relationship to nutritional status in the institutionalized elderly population. J A m Diet A ssoc 2006;106:112-14.

38. Rimm E B, A scherio A, Giovannucci E, Spigelman D, Stambfer MJ, W illet WC. V egetable, fruit and cereal fiber intake and risk of coronary heart disease among men. JAMA 1996 Feb $14 ; 275(6): 447-51$.

\section{ABOUT THE AUTHORS}

\section{Dheeraj Kumar (Corresponding Author)}

Professor, D epartment of Prosthodontics, Sardar Patel Post Graduate Institute of Dental and M edical Sciences, Lucknow, Uttar Pradesh India, e-mail: drdheerajkumarb@gmail.com

\section{Namrata Rastogi}

Professor, Department of Orthodontics, Sardar Patel Post Graduate Institute of Dental and Medical Sciences, Lucknow, Uttar Pradesh India

\section{Ravi Madan}

Reader, Department of Prosthodontics, Kothiwal Dental College M oradabad, Uttar Pradesh, India 